Rev. Bras. Saúde Prod. Anim., Salvador, v.13, n.3, p.642-655 jul./set., 2012 http://www.rbspa.ufba.br ISSN 15199940

\title{
Suplementação como Estratégia de Produção de Carne de Qualidade em Pastagens Tropicais ${ }^{1}$
}

\author{
Supplementation as a strategy for the production of the beef quality in tropical pastures
}

\author{
REIS, Ricardo Andrade ${ }^{2 *}$; RUGGIERI, Ana Claudia ${ }^{2}$; OLIVEIRA, Andre Alves ${ }^{3}$; \\ AZENHA, Mariana Vieira ${ }^{3 *}$; CASAGRANDE, Daniel Rume ${ }^{4}$
}

\author{
${ }^{1}$ Revisão apresentada no Congresso Brasileiro de Zootecnia (ZOOTEC 2011). \\ ${ }^{2}$ Universidade Estadual Paulista, Faculdade de Ciências Agrárias e Veterinária, Jaboticabal, São Paulo, Brasil. \\ ${ }^{3}$ Universidade Estadual Paulista, Faculdade de Ciências Agrárias e Veterinária, Programa de Pós \\ Graduação em Zootecnia, Jaboticabal, São Paulo, Brasil. \\ ${ }^{4}$ Universidade Federal de Lavras, Departamento de Zootecnia, Lavras, Minas Gerais, Brasil. \\ *Endereço para correspondência: rareis@ fcav.unesp.br
}

\section{RESUMO}

O manejo do pastejo e a suplementação estratégica permitem maximizar a produção de carne bovina em pastagens de forma sustentável. A intensidade de pastejo influencia diretamente o crescimento individual, taxas de aparecimento e mortalidade de perfilhos, a determinar o acúmulo de forragem e a estrutura do dossel. Dessa forma, nas águas, é função do manejo do pastejo adequar a frequência e intensidade de desfolhação para que o animal possa colher forragem com idade fisiológica e valor nutritivo adequados. A idade e tamanho dos perfilhos determinam a proporção de tecidos de suporte lignificados que reduzem a digestibilidade da forragem. No período seco, o manejo do pasto e a estratégia de diferimento, ao final do período das águas, são determinantes na obtenção de forragem de melhor valor nutritivo. Assim, o manejo das pastagens visa, primeiramente, à produção de forragens com altos teores de fibra potencialmente digestíveis. A partir de então, a caracterização da quantidade e qualidade da forragem são primordiais à adequação dos nutrientes fornecidos, via suplementos, para otimizar a utilização dos recursos forrageiros basais. A suplementação da dieta dos animais em pastejo, com concentrado, permite aumentar o desempenho dos animais, o que reduz a idade de abate e melhora a qualidade da carcaça e da carne obtida, além dos benefícios na preparação dos animais terminados em confinamento. Portanto, o manejo do pastejo e a suplementação da dieta dos animais permitem aumento de produtividade e maior qualidade dos produtos.

Palavras chaves: diferimento, manejo do pastejo, suplementos, valor nutritivo.

\section{SUMMARY}

Grazing management and strategic supplementation can maximize the production of beef cattle on pastures in a sustainable system. Grazing intensity affects directly on individual growth, appearance and mortality rate of tillers, and also determines the herbage accumulation and canopy structure. During the rainy season is a function of grazing management to adapt the frequency and intensity of defoliation, to supply the animal with forage in an appropriate physiological stage and nutritive value. The age and size of tillers determine the proportion of lignified tissues that will reduce the digestibility of forage. During dry season, the stockpiled pasture strategies at the end of the rainy season, will be crucial to obtaining forage of highest nutritive value. The pasture management primarily aims to produce forages with high levels of potentially digestible fiber. Since then, the characterization of the forage quantity and quality are essential to adjusting the nutrients supplied by supplements to optimize the available forage utilization. Supplementation of grazing beef cattle with concentrate can increase animal performance, reduce the slaughter age, and improve the quality of carcass and meat. Moreover, it has benefits in the preparation of the animals that will be finished in feedlot, and reducing this phase. Therefore, grazing management and supplementation of the animal diet should increase productivity, and improved carcass and beef quality.

Keywords: grazing management, nutritive value, stockpiled, supplements. 


\section{INTRODUÇÃO}

O grande desafio dos sistemas de produção de carne bovina em pastagens está na utilização de conhecimentos e alternativas tecnológicas capazes de elevar a produtividade e a qualidade do produto de forma sustentável, com baixo impacto ambiental. Para tanto, potencializar o desempenho dos animais e otimizar a utilização dos recursos forrageiros basais consistem nos principais objetivos de estratégias de manejo a serem adotadas.

O desempenho animal em pastagens é determinado principalmente pela qualidade da forragem, e esta por sua vez é função do valor nutritivo (VN) e consumo voluntário. Assim, o manejo do pastejo exerce papel primordial no contexto alimentar animal, isto é, quando as questões referentes à massa de forragem, estrutura do dossel forrageiro, oferta de folhas, colmo e material morto são fatores determinantes que afetam o comportamento ingestivo $\mathrm{e}$ consequentemente o consumo de nutrientes.

No entanto, raramente as pastagens tropicais conseguem manter um balanço ótimo entre as demandas animais e os nutrientes necessários para atender às exigências de ganhos elevados, mesmo no período favorável ao crescimento das plantas (primavera/verão), época de maior oferta em quantidade e qualidade de forragem. Essa variação entre $o$ suprimento e demanda de nutrientes ao longo do ano ocorre devido à estacionalidade na produção forrageira, na qual, redução na produção de forragem e mudanças estruturais do dossel, acúmulo de colmo e material morto, incita uma queda na qualidade da forragem na estação seca do ano (outono/inverno).
Nesse cenário, a utilização de suplementos concentrados seja na seca, seja nas águas, permite corrigir deficiências específicas de nutrientes na forragem para maximizar a utilização pelos micro-organismos ruminais $\mathrm{e}$ potencializar o ganho de peso. Acrescenta-se ainda a melhora na qualidade da carcaça e da carne obtida, além dos benefícios na preparação dos animais terminados em confinamento, além de encurtar esta fase.

Portanto, objetivou-se discutir o impacto do manejo das pastagens e da suplementação sobre as características quali-quantitativas da forragem produzida e das características dos nutrientes a serem fornecidos, via suplementos, sobre o desempenho de bovinos de corte mantidos em pastagens. Além de definir estratégias de manejo que permitam aumentar a produtividade do sistema e a produção de animais precoces com maior qualidade de carcaça e de carne.

\section{MANEJO $X$ PRODUÇÃO DE FORRAGEM DE QUALIDADE}

No ecossistema pastagem, o controle da desfolha é um fator determinante da sustentabilidade do mesmo, principalmente, por se tratar de um evento de caráter antagônico, ou seja, a planta utiliza as folhas para captar luz e realizar fotossíntese, o que produz carboidratos responsáveis pela manutenção da vida e desenvolvimento. Por outro lado, estas são uma fração da planta forrageira que compõem a maior parte da dieta de animais em pastejo (CASAGRANDE, 2010).

Trabalhos recentes, nos quais utilizaram a lotação contínua (CASAGRANDE et al 2011), reportam a facilidade e a importância do manejo do pasto, com base na altura do dossel sobre as 
respostas de plantas e animais. A adoção da altura como critério do manejo, permite o controle da massa de forragem e da taxa de lotação que, por sua vez, favorece a determinação simultânea da qualidade e da quantidade de forragem e a manutenção da sustentabilidade do sistema.

Estudos conduzidos na FCAV/UNESP, Campus de Jaboticabal, têm gerado dados consistentes sobre os efeitos de diferentes alturas de manejo de pasto no período das águas. Nessa linha de pesquisa, Azenha (2010) avaliou pastos de capim-marandu (Brachiaria brizantha (Hochst ex A. Rich) Stapf cv. Marandu) em sistema de pastejo de lotação contínua, e carga variável, em três alturas: 15,25 e $35 \mathrm{~cm}$. Nesse estudo, a autora observou as maiores taxas de senescência e de alongamento de folhas na maior altura de pastejo. Assim, a elevação do crescimento de forragem, sob pastejo leniente, está relacionado ao maior índice de área foliar, os quais interceptam grande quantidade de radiação solar. Em dossel mantido com baixa altura, o crescimento e a senescência são reduzidos e apontam um menor acúmulo de forragem.

As respostas observadas no acúmulo de forragem em diferentes intensidades de pastejo estão correlacionadas, diretamente, com crescimento individual, taxas de aparecimento e mortalidade de perfilhos. O pastejo é a principal causa de morte destes, de modo que as respostas das plantas quanto à reposição de perfilhos mortos precisam ser conhecidas para que práticas de manejo adequadas possam ser idealizadas e desenvolvidas.

Azenha (2010) concluiu que com o aumento da altura do dossel houve acréscimo no crescimento individual de perfilhos, contudo, a densidade destes diminuiu. Com o aumento da altura, verificou-se crescimento do intervalo de visitação dos animais aos perfilhos, ou seja, levaram mais dias para visitar o mesmo perfilho. Casagrande et al (2011) avaliou pastos de capimmarandu manejados sob lotação contínua, nas alturas de 15,25 e $35 \mathrm{~cm}$, e registrou o comportamento ingestivo de novilhas. $O$ autor verificou que a média do tempo de pastejo dos animais nos pastos de capim-marandu, mantidos em altura de $15 \mathrm{~cm}$, foi de 7,3 horas, seguido de 6,4 horas, na altura de $25 \mathrm{~cm}$, e 5,5 na altura de $35 \mathrm{~cm}$. Esse fato pode explicar o menor intervalo de visitações na menor altura. Deve-se destacar que a maior taxa de lotação utilizada na altura de $15 \mathrm{~cm}$ também pode ter influenciado no intervalo de visitação aos perfilhos nessa altura.

Desse modo, um pasto mantido sob lotação contínua e eficientemente manejado, no qual os animais estejam continuamente sujeitos à dietas com folhas jovens faz com que a digestibilidade da forragem consumida seja mantida em patamar mais elevado em relação à lotação intermitente.

É função do manejo do pastejo adequar a frequência e intensidade de desfolhação para que o animal possa colher forragem com idade fisiológica adequada. A idade e tamanho dos perfilhos determinam a proporção de tecidos de suporte lignificados, como esclerênquima e xilema. Adicionalmente, o parênquima apresenta alta propensão à lignificação e exerce grande influência na redução da digestibilidade das gramíneas com maturidade avançada, visto ser rapidamente degradável, em colmos jovens, e se torna indigestível com a evolução da idade da planta (AKIN, 1989).

Desse modo, tecidos de baixa digestão correlacionam-se negativamente com os teores de proteína bruta (PB) e digestibilidade in vitro da matéria seca (DIVMS), enquanto, positivamente com os teores de fibra e de lignina. 
Rev. Bras. Saúde Prod. Anim., Salvador, v.13, n.3, p.642-655 jul./set., 2012 http://www.rbspa.ufba.br ISSN 15199940

Aqueles rapidamente digeridos mostram correlações positivas com a PB e com a DIVMS e negativas com os teores de fibra e lignina (CARVALHO \& PIRES, 2008).

Queiroz et al. (2000) avaliaram as folhas e o colmo do topo e da base de perfilhos de três gramíneas forrageiras e encontraram correlações positivas entre a proporção de bainha parenquimática dos feixes, tecido vascular lignificado e esclerênquima com os teores de FDN,
FDA e lignina das plantas. Já as proporções de mesófilo e epiderme correlacionaram-se negativamente.

Pastos manejados sob diferentes intensidades promovem respostas tanto no acúmulo de massa, quanto no VN. Casagrande (2010) avaliou pastos de capim-marandu manejados sob lotação contínua nas alturas de 15,25 e $35 \mathrm{~cm}$ e encontrou redução no teor de $\mathrm{PB}$ e aumento na fibra, à medida que elevou a altura do pasto (Tabela 1 ).

Tabela 1. Composição química de capim-marandu, amostras de pastejo simulado de novilhas Nelore, em função das alturas do dossel, no período das águas

\begin{tabular}{lcccc}
\hline \multirow{2}{*}{ Variáveis } & \multicolumn{3}{c}{ Altura do dossel (cm) } & CV $(\%)$ \\
\cline { 2 - 4 } MM (\% MS) & 15 & 25 & 35 & 7,8 \\
MO (\% MS) & $10,4^{\mathrm{a}}$ & $9,6^{\mathrm{b}}$ & $9,5^{\mathrm{b}}$ & 0,8 \\
PB (\% MS) & $89,6^{\mathrm{b}}$ & $90,4^{\mathrm{a}}$ & $90,5^{\mathrm{a}}$ & 11,5 \\
F A (\% PB) & $15,7^{\mathrm{a}}$ & $15,7^{\mathrm{a}}$ & $14,3^{\mathrm{b}}$ & 18,2 \\
F B1+B2 (\% PB) & 47,2 & 46,1 & 51,0 & 30,5 \\
F B3 (\% PB) & 24,7 & 28,8 & 25,4 & 51,0 \\
F C (\% PB) & 22,9 & 19,6 & 19,2 & 42,1 \\
FDNcp (\% MS) & 5,2 & 5,5 & 4,4 & 3,2 \\
FDA (\% MS) & $57,5^{\mathrm{b}}$ & $59,0^{\mathrm{ab}}$ & $60,2^{\mathrm{a}}$ & 10,2 \\
Lig (\% MS) & 34,7 & 34,8 & 35,6 & 18,9 \\
CNF (\% MS) & $5,7^{\mathrm{a}}$ & $5,0^{\mathrm{ab}}$ & $4,7^{\mathrm{b}}$ & 16,7 \\
EE (\% MS) & 14,8 & 14,0 & 14,4 & 28,9 \\
NDT (\% MS) & 1,6 & 1,6 & 1,6 & 13,5 \\
DIVMO (\% MS) & $69,7^{\mathrm{ab}}$ & $68,2^{\mathrm{b}}$ & $72,6^{\mathrm{a}}$ & 6,3 \\
g PB/kg MOD & $77,2^{\mathrm{ab}}$ & $75,1^{\mathrm{b}}$ & $79,3^{\mathrm{a}}$ & 6,9
\end{tabular}

Médias seguidas pela mesma letra minúscula na linha dentro de cada fator analisado não diferem entre si pelo teste de Tukey a $5 \%$ de probabilidade. $\mathrm{CV}=$ Coeficiente de variação.

$\mathrm{MM}=$ matéria mineral; $\mathrm{MO}=$ matéria orgânica; $\mathrm{PB}=$ proteína bruta; $\mathrm{F} \mathrm{A}$ = fração A da proteína bruta, nitrogênio não proteico; $\mathrm{F}$ B1+B2 = fração da proteína de alta e média degradação ruminal; $\mathrm{F}$ B3 = Fração da proteína bruta associada à fibra de lenta degradação; $\mathrm{F} \mathrm{C}=$ fração indigestível da proteína bruta; FDNcp = fibra em detergente neutro corrigida pra cinzas e proteína; FDA = fibra em detergente ácido. $\mathrm{Lig}=$ teor de lignina; $\mathrm{CNF}=$ carboidrato não fibroso; $\mathrm{EE}=$ extrato etéreo; $\mathrm{NDT}=$ nutrientes digestíveis totais; DIVMO = digestibilidade in vitro da matéria orgânica; g PB/kg MOD = relação entre proteína e matéria orgânica digestível. 
Pode-se inferir que o manejo adequado dos pastos nas alturas avaliadas, $25 \mathrm{e}$ $35 \mathrm{~cm}$, propiciou forragem de elevado VN. Dados coletados, nos anos de 2009 e 2011, por Vieira (2011) e Oliveira (dados não publicados), respectivamente, confirmam as observações de Casagrande (2010).

\section{DIFERIMENTO DE PASTAGENS}

A qualidade do pasto é o fator mais importante que influencia a produtividade de bovinos em pastejo e pode ser agravado durante a época seca do ano. $\mathrm{O}$ manejo de diferimento dos pastos resulta em alterações na planta, como o alongamento das hastes $\mathrm{e}$ florescimento, redução da proporção de folhas verdes, as quais atingem o valor nutrivo da forragem (SANTOS et al., 2010a), com a consequente redução no consumo. Assim, em pastagens diferidas, mesmo com elevada massa de forragem acumulada, a estrutura pode interferir no consumo dos animais, a resultar em quedas de desempenho.

As plantas mais indicadas para a prática de diferimento são aquelas, cujo VN sofre redução lenta ao longo do tempo, com baixo acúmulo de colmo e boa retenção de folhas verdes (EUCLIDES et al., 2007). Isso inclui espécies do gênero Brachiaria (decumbens, capimmarandu e capim-xaraés), Cynodon (capins estrela, coastcross e tifton) e Digitaria (capim-pangola). As gramíneas cespitosas, tais como os Pannicum (capins tanzânia, mombaça e tobiatã), Pennisetum (capim-elefante) e Andropogon (cvs. Planaltina e Baeti), quando diferidas por períodos longos, apresentam acúmulo excessivo de colmos grossos e baixa relação folha:colmo, o que as tornam não indicáveis para a vedação por longos períodos.
Pastos com maiores taxas de crescimento e diferidos por longos períodos podem acamar, principalmente aqueles, cujos colmos são delgados e flexíveis, como os do gênero Brachiaria, o que resulta em estrutura inadequada ao consumo (SANTOS et al., 2009). O índice de tombamento do pasto correlaciona-se positivamente com as massas de forragem total, forragem morta e colmo morto, enquanto, negativamente com as massas de forragem verde e de lâmina foliar verde. Também se correlaciona de forma negativa com o número de perfilhos vegetativos, mas de forma positiva com o número de perfilhos mortos e reprodutivos. As ações de manejo que resultam em pastos diferidos com estágio de maturidade mais avançado, com maior ocorrência de perfilhos reprodutivos e mortos, em detrimento de perfilhos vegetativos, contribuem para aumentar o tombamento e diminuir a eficiência de pastejo (SANTOS et al., 2010b).

Santos et al. (2010b), avaliaram correlações entre número de perfilhos, índice de tombamento, massa dos componentes morfológicos e $\mathrm{VN}$ de forragem em pastos diferidos de capimbraquiaria (Brachiaria decumbens, Stapf) e encontraram correlação positiva entre o componente morfológico, massa de lâmina foliar verde, com os porcentuais de $\mathrm{PB}$, fibra em detergente neutro, potencialmente digestível (FDNpd), e MSpd e negativa com a FDN e FDNi. Também encontraram correlação positiva entre massa de lâmina foliar morta e FDNpd, o que lhes permitiu concluir que lâminas foliares mortas constituem alimento energético para o animal durante o período da seca. Nesse mesmo experimento, a massa de colmos mortos foi correlacionada negativamente com os teores de PB, FDNpd e MSpd e, positivamente com os teores de FDN e FDNi. 
Assim, os componentes morfológicos determinantes na qualidade do pasto diferido são principalmente lâminas foliares verdes e colmos mortos.

Portanto, quando se almeja ofertar forragem em quantidade e qualidade, na época seca do ano, o manejo do pasto e a estratégia de diferimento no final do período das águas são determinantes na obtenção de forragem de melhor VN.

\section{OTIMIZAÇÃO DOS RECURSOS FORRAGEIROS COM USO DE SUPLEMENTOS}

Os resultados de pesquisas sobre $\mathrm{o}$ manejo de pastagens e utilização de suplementos proteicos-energéticos evidenciam a forte associação entre disponibilidade de folha e ganho de peso. Vários autores já descreveram a importância da quantidade de folhas verdes sobre a qualidade da ingesta (SANTOS et al., 2004; EUCLIDES et al., 2000).

Euclides et al. (2000), por exemplo, notaram a seletividade animal, ou seja, sua preferência por folhas em relação a caules e material morto. Desse modo, potencializar a utilização da forragem, através do manejo do pastejo e suplementação concentrada estratégica, a fim de aumentar a taxa de lotação e, principalmente, o ganho de peso animal torna-se ferramenta de manejo indispensável. Tal acréscimo acarreta menor tempo para atingir peso de abate, reduzir a permanência do animal na propriedade e, consequentemente, diminuir o número de estações secas na vida do animal, além de otimizar o sistema. Para isso, deve-se procurar equacionar o suprimento de forragem de qualidade e nutrientes limitantes, via suplementos, com a demanda animal para a meta de produção preconizada.
Uma vez que a forragem foi consumida pelo animal, a qualidade da fibra passa a ser o fator mais limitante à produção, demonstrado pela melhora no desempenho animal com pequenas mudanças na digestibilidade da forragem. Dessa forma, o manejo das pastagens visa, primeiramente, à produção de forragens com altos teores de FDN potencialmente digestíveis. A partir de então, a utilização da FDNpd pelos eventos de degradação ruminal ocorrem em escalas de tempo finitas $e$ impossibilita a exploração total dos substratos energéticos potencialmente disponíveis, mas permite a extração de apenas parte destes, a qual constitui a fração efetivamente degradada da FDN (FDNed). Assim, a utilização de recursos forrageiros e suplementares deve buscar a máxima aproximação entre a FDNed e a FDNpd, sem que ocorram, simultaneamente, implicações negativas sobre outros parâmetros do processo produtivo, como o consumo voluntário (PAULINO et al., 2006).

Otimizar a utilização da FDN pelos micro-organismos consiste no grande desafio dos nutricionistas. $\mathrm{Na}$ seca, o principal objetivo seria aumentar a utilização da FDNpd através da suplementação com compostos nitrogenados, devido principalmente, as forragens não apresentarem o mínimo necessário de $7 \%$, com base na matéria seca, de compostos nitrogenados para que os micro-organismos ruminais apresentem plena capacidade de degradação dos substratos fibrosos (LAZZARINI et al., 2009).

De acordo com Reis et al. (2009) mesmo se houver disponibilidade de fibra, potencialmente digestível, nos pastos na seca, a proteína é o nutriente mais limitante e deve ser corrigida através da suplementação a fim de aumentar a eficiência de degradação da fração fibrosa e, consequentemente, a 
taxa de passagem e o consumo de matéria seca da forragem.

No período das águas, quando as forragens são classificadas como de média a alta qualidade, com teores de compostos nitrogenados acima do mínimo recomendado para plena atividade das bactérias que utilizam os carboidratos estruturais, o objetivo da suplementação, associado à estratégias de manejo do pastejo não seria estímulos, mas sim a prevenção de efeitos deletérios na utilização da FDNpd (PAULINO et al., 2006).

De acordo com POPPI \& McLENNAN (1995), a alta degradabilidade da proteína da forragem, no período das águas, pode provocar perdas excessivas de compostos nitrogenados no ambiente ruminal, na forma de amônia, o que diminui a síntese de proteína microbiana e gera déficit proteico, em relação às exigências para ganhos elevados. Nesse contexto, as principais limitações para o crescimento microbiano ruminal residiriam no fato de a forragem disponível ao pastejo permitir baixa assimilação do nitrogênio disponível em proteína microbiana no rúmen, em função da alta degradabilidade dos compostos nitrogenados ou menor velocidade de degradação dos carboidratos fibrosos da forragem (DETMANN et al., 2005).

Nessas situações, o fornecimento de suplementos com fontes proteicas de baixa degradação ruminal, que ampliassem diretamente o suprimento de proteína metabolizável ao animal, ou o fornecimento de fontes energéticas de rápida disponibilidade no rúmen, otimizaria a assimilação microbiana do nitrogênio e poderia acarretar melhorias no desempenho animal (POPPI \& McLENNAN, 1995; DETMANN et al., 2005).

De acordo com Johnson et al. (2001) gramíneas tropicais, manejadas intensivamente com doses elevadas de nitrogênio (200 a $500 \mathrm{~kg} / \mathrm{N} / \mathrm{ha}$ ), durante o período das águas, possuem cerca de 40 a $50 \%$ de conteúdo de compostos nitrogenados na forma solúvel. Esse fato, aliado ao alto conteúdo de carboidratos estruturais com menores taxas de degradação, promove falta de sincronia entre nitrogênio e esqueletos de carbonos, oriundos da degradação de carboidratos no rúmen, a desfavorecer a síntese de proteína microbiana.

Pastagens manejadas intensivamente com aplicação de nitrogênio podem apresentar elevados teores de compostos nitrogenados, o que favorece respostas positivas da suplementação energética. Contudo, Correia (2006), ao analisar uma compilação de dados de vários trabalhos com suplementação energética no período das águas, chegou à conclusão de que se a forragem apresentasse teores de PB menores que $11 \%$ não seriam verificadas respostas da suplementação energética. No entanto, existe um trabalho que apresentou forragem entre 15 a $18 \%$ de $\mathrm{PB}$ com altos teores de nitrogênio não proteico, cujo autor (RAMALHO, 2006) observou respostas à suplementação energética.

Os resultados disponíveis na literatura com estudo de suplementação energética nas águas são muitos contraditórios. Várias questões ainda não foram totalmente compreendidas devido ao fato de não possuírem entendimento completo dos fatores que interagem, tais como, teor de proteína no suplemento, exigências de $\mathrm{N}$ pelos micro-organismos ruminais, forma física do suplemento $\mathrm{e}$ características de nutrientes a ser utilizado, amido ou fibra altamente digestível, e os efeitos sobre a utilização dos componentes fibrosos da forragem.

Nesse sentido, Costa et al. (2008) avaliaram a degradação in vitro da FDN de forragens de alta qualidade $(11 \%$ PB), em função da suplementação com carboidratos e/ou proteína, e apontaram 
o uso exclusivo de carboidratos (amido ou pectina) como responsável pelo efeito inibitório sobre a taxa de degradação da FDNpd. Contudo, a utilização de amido e caseína permitiu a manutenção da taxa de degradação da FDNpd.

Pesquisas conduzidas na FCAV/UNESP, Campus de Jaboticabal, têm gerado informações relevantes sobre estratégias de suplementação no período das águas. Casagrande (2010), no ciclo (2007/2008), avaliou três alturas de pastejo $(15 ; 25$ e 35 $\mathrm{cm})$ em capim-marandu e três tipos de suplemento, a saber: sal mineral (SM) ad libtum e dois suplementos proteicos com diferentes relações de PDR:energia, fornecidos em uma quantidade de 0,3\% $\mathrm{PV} /$ dia. Ambos os suplementos possuíam 26,6\% de PB e $82 \%$ de NDT. Ocorre que o suplemento com alta relação PDR/energia possuía teor de PDR de 76,8\% (\%PB), enquanto $\mathrm{O}$ suplemento com baixa relação PDR/energia foi formulado, de modo a fornecer 52,2\% de PDR (\%PB). Os resultados demonstraram que não houve diferenças no desempenho dos animais em resposta aos suplementos com diferentes relações de PDR/NDT. No entanto, a suplementação de $0,3 \%$ do $\mathrm{PV} /$ dia (SPT), independente do suplemento utilizado, elevou o ganho de peso médio diário (GMD) em todas as alturas, porém o ganho adicional foi inferior nos pastos mantidos mais altos. (Tabela 2).

Vieira (2011) trabalhou na mesma área experimental e obteve resultados preliminares no ciclo 2008/2009, em igual contexto de alturas de pastejo, e suplementação com sal mineral, suplementação energética $(0,3 \% \mathrm{PV})$ e suplementação proteica $(0,3 \% \mathrm{PV})$, isto é, respostas semelhantes às do ciclo anterior. Foram observados ganhos por animal em resposta à suplementação energética e proteica, superiores à suplementação exclusiva com sal mineral. Portanto, a suplementação com energia e/ou proteína pode ser estabelecida de acordo com o VN da forragem, intimamente ligado à estratégia de manejo do pasto.

Tabela 2. Peso inicial (PCi) e final (PCf) e desempenho animal de novilhas Nelore mantidas em pastos de capim-marandu, manejado com três alturas, sujeitas a diferentes tipos de suplementação nas águas

\begin{tabular}{lccccccr}
\hline \multirow{2}{*}{ Variáveis } & \multicolumn{3}{c}{ Altura do dossel } & \multicolumn{3}{c}{ Suplementos } & \multirow{2}{*}{ CV } \\
\cline { 2 - 6 } & 15 & 25 & 35 & SM & SPEA & SPEB & \\
\hline PCi (kg) & 214 & 216 & 212 & 214 & 213 & 215 & 7,4 \\
PCf (kg) & $273^{\mathrm{b}}$ & $287^{\mathrm{a}}$ & $295^{\mathrm{a}}$ & $273^{\mathrm{b}}$ & $289^{\mathrm{a}}$ & $293^{\mathrm{a}}$ & 8,7 \\
GP (g/dia) & $511^{\mathrm{b}}$ & $608^{\mathrm{ab}}$ & $713^{\mathrm{a}}$ & $505^{\mathrm{b}}$ & $653^{\mathrm{a}}$ & $674^{\mathrm{a}}$ & 22,6 \\
TL (UA/ha) & $5,8^{\mathrm{a}}$ & $4,5^{\mathrm{b}}$ & $3,4^{\mathrm{c}}$ & $4,3^{\mathrm{b}}$ & $4,7^{\mathrm{a}}$ & $4,7^{\mathrm{a}}$ & 6,0 \\
GA (kg/ha) & $636^{\mathrm{a}}$ & $568^{\mathrm{ab}}$ & $498^{\mathrm{b}}$ & $453^{\mathrm{b}}$ & $619^{\mathrm{a}}$ & $630^{\mathrm{a}}$ & 23,1 \\
GAOL (cm $\left.{ }^{2}\right)$ & $8,9^{\mathrm{b}}$ & $13,6^{\mathrm{a}}$ & $14,9^{\mathrm{a}}$ & $10,6^{\mathrm{b}}$ & $13,2^{\mathrm{a}}$ & $13,5^{\mathrm{a}}$ & 17,0 \\
\hline
\end{tabular}

Médias seguidas pela mesma letra minúscula na linha dentro de cada fator analisado não diferem entre si pelo teste de Tukey a $5 \%$ de probabilidade. $\mathrm{CV}=$ coeficiente de variação.

$\mathrm{GP}=$ ganho de peso diário; TL = taxa de lotação; GA = ganho por área; GAOL = ganho área de olho de lombo; SM = sal mineral; SPEA = suplemento proteico-energético com alta relação proteína degradável no rúmen $(\mathrm{PDR}) /$ nutriente digestíveis totais (NDT); SPEB = suplemento proteico energético com baixa relação PDR/NDT.

Adaptado de Casagrande (2010). 


\section{IMPLICAÇÕES DO MANEJO DO PASTO E DA SUPLEMENTAÇÃO NA PRODUÇÃO DE BOVINOS PRECOCES}

A redução da idade de abate é um fator importante dentro do sistema de produção, pois além de propiciar melhoras nos índices produtivos $\mathrm{e}$ econômicos, gera um produto de melhor qualidade. $\mathrm{O}$ abate de animais jovens (precoce) propicia carne com maior maciez e suculência, características cada vez mais exigidas pelo mercado consumidor. Na tentativa de atender a esse mercado, diversos grupos de pesquisa, no Brasil, têm trabalhado para reduzir a idade de abate dos animais, seja com uso de confinamentos e suplementação, seja com melhoras no manejo da pastagem.

Casagrande (2010) realizou experimentos no intuito de reduzir a idade de abate de novilhas de corte, sujeitas a pastos de capim-marandu e suplementação na recria e mantidas em dois sistemas de terminação, confinamento e no pasto. $\mathrm{Na}$ recria, $\mathrm{o}$ autor manteve os animais suplementados com sal mineral, ou 0,3\% PV de suplemento proteico energético, sob pastejo em lotação contínua, com dosséis mantidos em três alturas, 15; 25 e $35 \mathrm{~cm}$. Em tais condições, o autor observou aumento do desempenho individual nos animais mantidos em pastos com maior altura, entretanto, a taxa de lotação foi menor, o que possibilitou maior desempenho por área nos pastos mantidos a $15 \mathrm{~cm}$ de altura. $\mathrm{O}$ suplemento proteicoenergético proporcionou incremento no desempenho, na taxa de lotação e, consequentemente, no ganho por área. O maior ganho de peso, promovido pela suplementação proteica-energética e pela maior altura do pasto, refletiu em ganho de carcaça e em incremento na área de olho de lombo.

$\mathrm{Na}$ fase de terminação, os animais foram submetidos a dois sistemas, um no pasto e outro no confinamento, no qual o critério para abate era o peso das novilhas, isto é, a partir de $360 \mathrm{~kg}$. Os animais terminados em confinamento foram os primeiros a serem abatidos, de forma que aqueles mais pesados, provenientes da fase de recria, foram sacrificados primeiro.

Verificou-se efeito compensatório em relação às alturas do dossel: os animais, mantidos em $15 \mathrm{~cm}$ de altura, que ganharam pouco peso na recria tiveram maior desempenho no confinamento. Os animais assentados nos pastos de menor altura demoraram em média 12 dias a mais do que os demais integrantes da recria, em pastos com $35 \mathrm{~cm}$ de altura (Tabela 3). Portanto, manter os animais em pastos com maior altura na recria pode diminuir o tempo de confinamento, o que reduz o custo com essa fase. Entretanto, sistemas, cuja altura do dossel for $15 \mathrm{~cm}$, podem priorizar o ganho por área, de modo a elevar a taxa de lotação em $70 \%$ em relação ao aumento da altura do dossel para $35 \mathrm{~cm}$. Assim, a utilização desses sistemas pode levar ao abatimento de maiores números de animais, com aumento de apenas 12 dias de confinamento, e, assim, gerar lucros.

A suplementação proteico-energético, na recria, diminuiu em 16 dias o período de confinamento, além disso, propiciou a elevação de $9 \%$ na taxa de lotação, portanto, os custos da suplementação possivelmente são pagos com ganhos no sistema, ou seja, o elevado número de animais abatidos e a redução do tempo de confinamento. 
Rev. Bras. Saúde Prod. Anim., Salvador, v.13, n.3, p.642-655 jul./set., 2012 http://www.rbspa.ufba.br ISSN 15199940

Tabela 3. Desempenho de novilhas Nelore, recriadas em pastagem de capim-marandu, com diferentes alturas de dossel e suplementadas com sal mineral ou suplemento proteico-energético e terminadas no confinamento ou no pasto

\begin{tabular}{|c|c|c|c|c|c|c|}
\hline \multirow{2}{*}{ Variáveis } & \multicolumn{3}{|c|}{ Altura do dossel } & \multicolumn{2}{|c|}{ Suplemento } & \multirow{2}{*}{$\begin{array}{l}\mathrm{CV} \\
(\%)\end{array}$} \\
\hline & 15 & 25 & 35 & SM & SPE & \\
\hline \multicolumn{7}{|c|}{ Terminação no confinamento } \\
\hline Ganho de peso (g/dia) & $999^{\mathrm{a}}$ & $967^{\mathrm{ab}}$ & $854^{\mathrm{b}}$ & 951 & 922 & 13,2 \\
\hline Dias para terminação (dias) & $101^{\mathrm{a}}$ & $91^{\mathrm{ab}}$ & $89^{\mathrm{b}}$ & $102^{\mathrm{a}}$ & $86^{\mathrm{b}}$ & 24,6 \\
\hline \multicolumn{7}{|c|}{ Terminação no pasto } \\
\hline Ganho de peso (g/dia) & $406^{\mathrm{a}}$ & $342^{b}$ & $341^{\mathrm{b}}$ & 375 & 350 & 13,2 \\
\hline Dias para terminação (dias) & $271^{\mathrm{a}}$ & $225^{\mathrm{b}}$ & $234^{\mathrm{b}}$ & $256^{\mathrm{a}}$ & $231^{\mathrm{b}}$ & 28,4 \\
\hline
\end{tabular}

Médias seguidas por mesma letra minúscula dentro de cada fator de estudo não diferem entre si pelo teste de Tukey a $5 \%$ de probabilidade.

$\mathrm{CV}=$ coeficiente de variação. $\mathrm{SM}=$ sal mineral. $\mathrm{SPE}=$ suplemento proteico-energético.

Adaptado de Casagrande (2010).

Quando os animais foram terminados no pasto, com $0,5 \% \mathrm{PV} /$ dia de suplemento proteico-energético, as respostas foram semelhantes, no entanto, foram necessários cinco a seis meses a mais para os animais atingirem o peso predeterminado para o abate. Nesse tipo de sistema de terminação, os animais, mantidos em pastos de $15 \mathrm{~cm}$ de altura, na recria, necessitaram em média dois meses a mais para serem abatidos. Isso indica que mesmo com ganho compensatório, este foi pequeno para possibilitar a ocorrência do abate dos animais em pouco intervalo de tempo (Tabela 3 ).

Embora os fatores estudados durante a recria tenham interferido na idade de abate, não influenciaram as características da carcaça, nem da qualidade de carne. Já os sistemas de terminação interferiram na deposição de gordura na carcaça, uma vez que os animais confinados apresentaram maiores quantidade de gordura subcutânea, de forma que $80 \%$ das carcaças dos animais confinados foram classificadas como uniformes, enquanto, dos animais do pasto, $71 \%$ das carcaças foram classificadas como medianas. Assim, o rendimento de cortes cárneos foi maior nos animais terminados no pasto, em função da menor limpeza de gordura, contudo, o peso dos principais cortes cárneos foi similar entre os sistemas de terminação. Todavia, as peças dos animais confinados apresentaram maior cobertura de gordura, de forma que foram mais bem classificadas em relação às dos terminados no pasto (Tabela 4). A melhor classificação das peças dos animais confinados implica grande valorização pelo mercado.

Resende et al. (2008) trabalharam com novilhos durante a fase de recria e terminação com diferentes esquemas de suplementação e de terminação (confinamento e no pasto) e observaram que o uso de suplemento proteicoenergético, fornecido a $0,5 \% \mathrm{PV} / \mathrm{dia}$, tanto na seca, como nas águas, reduziram a idade de abate de novilhos de cruzamento industrial, abatidos com $500 \mathrm{~kg}$ de peso corporal. Houve redução de mais de 100 dias na idade de abate de animais confinados em relação aos terminados no pasto. 
Rev. Bras. Saúde Prod. Anim., Salvador, v.13, n.3, p.642-655 jul./set., 2012 http://www.rbspa.ufba.br ISSN 15199940

Tabela 4. Características de carcaça e rendimento dos principais cortes cárneos de novilhas Nelore recriadas em pastagem de capim-marandu, com diferentes alturas de dossel, suplementadas com sal mineral ou suplemento proteicoenergético e terminadas no confinamento ou no pasto

\begin{tabular}{lcccccccc}
\hline \multirow{2}{*}{ Variáveis } & \multicolumn{3}{c}{ Altura do dossel $(\mathrm{cm})$} & \multicolumn{2}{c}{ Suplementos } & \multicolumn{2}{c}{ Terminação } & CV \\
\cline { 2 - 7 } & 15 & 25 & 35 & SM & SPE & Conf & Pasto & $(\%)$ \\
\hline AOL $\left(\mathrm{cm}^{2}\right)$ & 58,4 & 60,5 & 61,2 & 59,0 & 61,1 & 59,0 & 61,1 & 10,5 \\
AOLC & 29,5 & 31,0 & 31,3 & 30,4 & 30,8 & 29,5 & 31,7 & 10,6 \\
$\left(\mathrm{~cm}^{2} / 100 \mathrm{~kg}\right)$ & 4,59 & 5,10 & 5,31 & 5,10 & 4,90 & $6,05^{\mathrm{a}}$ & $3,95^{\mathrm{b}}$ & 34,0 \\
EGS (mm) & 3,95 & 3,87 & 4,12 & 4,04 & 3,92 & $4,90^{\mathrm{a}}$ & $3,05^{\mathrm{b}}$ & 27,4 \\
GRPI (kg) & 51,1 & 50,8 & 51,2 & 51,2 & 50,9 & 50,8 & 51,3 & 2,0 \\
TR (\% PCF) & 38,0 & 37,9 & 37,7 & 37,7 & 38,0 & 38,0 & 37,7 & 2,6 \\
DI (\% PCF) & 10,9 & 11,3 & 11,1 & 11,1 & 11,1 & 11,2 & 11,0 & 6,1 \\
PA (\% PCF) & 26,78 & 27,17 & 26,97 & 26,83 & 27,12 & $27,59^{\mathrm{a}}$ & $26,41^{\mathrm{b}}$ & 4,3 \\
RCB (\% do TR) & 77,9 & 77,2 & 77,4 & 77,9 & 77,2 & $75,9^{\mathrm{b}}$ & $79,1^{\mathrm{a}}$ & 2,9 \\
RL (\%) & 20,8 & 21,0 & 20,9 & 20,9 & 20,9 & 20,9 & 20,9 & 4,4 \\
RCA (\% do TR)
\end{tabular}

Médias seguidas por mesma letra minúscula dentro de cada fator de estudo não diferem entre si pelo teste de Tukey a $5 \%$ de probabilidade.

$\mathrm{SM}=$ sal mineral; $\mathrm{SPE}=$ suplemento proteico-energético; $\mathrm{AOL}=$ área de olho de lombo; $\mathrm{GP}=$ área de olho de lombo relativa; EGS = espessura de gordura subcutânea dorsal; GRPI = gordura renal, pélvica e inguinal; TR = porcentagem de traseiro especial em relação a carcaça fria; DI = porcentagem de dianteiro em relação à carcaça fria; $\mathrm{TR}=$ porcentagem de ponta de agulha em relação à carcaça fria; $\mathrm{RCB}=$ rendimento bruto dos principais cortes cárneos do traseiro especial (noix, contra filé, filé mignom, miolo da alcatra e picanha) em relação ao traseiro; $\mathrm{RL}$ = rendimento de limpeza dos cortes cárneos (peso bruto/ peso após limpeza); $\mathrm{RCL}$ = rendimento após limpeza dos principais cortes cárneos do traseiro especial em relação ao traseiro; $\mathrm{CV}$. . Coeficiente de variação.

Adaptado de Casagrande (2010)

A grande diferença no tempo para abate animais terminados no pasto e no confinamento ocorre, entre outros fatores, em função da sazonalidade de produção de forragem, pois, enquanto os animais terminados no confinamento possuem dieta de alta qualidade, os animais mantidos em pastos estão sujeitos às ofertas temporais, no período da seca, por exemplo, os pastos caracterizam-se pela baixa produção de forragem e pelo reduzido VN. Na busca por abater animais precoces no pasto, o desmame com maior peso é fundamental, pois permite que o animal atinja o peso de abate antes de entrar na segunda seca de sua vida. Para isso, pode-se lançar mão do creep feeding como forma de permissão ao desmame do animal a partir dos $240 \mathrm{~kg}$ ou mais.
Além disso, aliado ao programa crescente de ganho de peso, com base no uso de suplementação concentrada e manejo do pastejo, permite que ao final do segundo período de águas do animal, este tenha $450 \mathrm{~kg}$ de peso corporal.

Com base no exposto pode-se inferir que independente do sistema de produção escolhido pode-se produzir carne com qualidade, com o uso de manejo do pastejo, suplementação concentrada ou com confinamento estratégico.

O manejo do pastejo com vistas a maximizar a produção de estrato pastejável, com alto conteúdo de FDNpd, atende, ao mesmo tempo, os critérios relativos à persistência do pasto e à qualidade da forragem. A adoção de estratégias de manejo das 
Rev. Bras. Saúde Prod. Anim., Salvador, v.13, n.3, p.642-655 jul./set., 2012 http://www.rbspa.ufba.br ISSN 15199940

pastagens e suplementação propicia aos animais condições para expressar o potencial genético para ganho de peso, ao longo do ano, durante as estações de águas e seca. Essa prática permite o abate de animais jovens, com carne de qualidade, sem deixar de atender às exigências do mercado consumidor. Ademais, nos sistemas de manejo do pastejo, nos quais se busca otimizar o desempenho por animal e por área, é possível, de maneira eficiente, minimizar os impactos ambientais da produção de bovinos de corte em pastagens de gramíneas tropicais.

\section{REFERÊNCIAS}

AKIN, D.E. Histological and phisical factors affecting digestibility of forages. Agronomy Journal, v.89, n.1, p.17 25,1989

\section{AZENHA, M.V. Morfogênese e dinâmica do perfilhamento do capim- marandu submetido à alturas de pastejo em lotação contínua com e sem suplementação. 2010. 93p. Dissertação (Mestrado em Zootecnia) - Universidade Estadual Paulista, Faculdade de Ciências Agrárias e Veterinária, Jaboticabal.}

CARVALHO, G.G.P.; PIRES, A.J.V. Organização dos tecidos de plantas forrageiras e suas implicações para os ruminantes Archivos de Zootenia, v.57, p.13-28, 2008.

\section{CASAGRANDE, D.C. Suplementação de novilhas de corte em pastagem de capim-marandu submetidas a intensidade de pastejo sob lotação contínua. 2010. 127p. Tese (Doutorado em Zootecnia) - Universidade Estadual Paulista, Faculdade de Ciências Agrárias e Veterinária, Jaboticabal.}

CASAGRANDE, D.R.; AZENHA, M.V.; VALENTE, A.L.S.; VIEIRA, B.R.; MORETTI, M.H.; RUGGIERI, A.C.; BERCHIELLI, T.T.; REIS, R.A. Canopy characteristics and behavior of Nellore heifers in Brachiaria brizantha pastures under different grazing heights at a continuous stocking rate. Revista Brasileira de Zootecnia, v.40, n.11, p.2294-2301, 2011.

\section{CORREIA, P.S. Estratégias de} suplementação de bovinos de corte em pastagens durante o período das águas. 2006. 334f. Tese (Doutorado em Ciência Animal e pastagens) - Universidade de São Paulo, Escola Superior de Agricultura Luiz de Queiroz, Piracicaba.

COSTA, V.A.C.; DETMANN, E.; VALADARES FILHO, S.C.; PAULINO, M.F.; HENRIQUES, L.T.; MANTOVANI, H.C. Degradação in vitro da fibra em detergente neutro de forragem tropical de baixa qualidade em função de suplementação com proteína e/ou carboidratos. Revista Brasileira de Zootecnia, v.37, n.3, p.494-503, 2008.

DETMANN, E.; PAULINO, M. F.; CECON, P.R.; VALADARES FILHO, S.C.; ZERVOUDAKIS, J.T.; CABRAL, L.S. LEAO, M.I.;LANA,R.P.; PONCIANO, N.J. Níveis de proteína bruta em suplementos para terminação de bovinos em pastejo durante o período de transição seca-águas: Consumo voluntário e trânsito de partículas.

Revista Brasileira de Zootecnia, v.34, n.4, p.1380-1391, 2005.

EUCLIDES, V.P.B; CARDOSO, E.G.; MACEDO, M.C.M.; OLIVEIRA, M.P. Consumo Voluntário de Brachiaria decumbens cv. Basilisk e Brachiaria brizantha cv. Marandu sob Pastejo. Revista Brasileira de Zootecnia, v.29, n.8, p.2200-2208, 2000. 
Rev. Bras. Saúde Prod. Anim., Salvador, v.13, n.3, p.642-655 jul./set., 2012 http://www.rbspa.ufba.br ISSN 15199940

EUCLIDES, V.P.B.; FLORES, R.; MEDEIROS, R.N.; OLIVEIRA, M.P. Diferimento de pastos de braquiária cultivares Basilisk e Marandu, na região do Cerrado. Pesquisa

Agropecuária Brasileira, v.42, n.2, p.273-280, 2007.

JOHNSON, C. R.; REILING, B.A.; MISLEVY, P.; HALL, M.B; Effects of nitrogen fertilization and harvest date on yield, digestibility, fiber, and protein fractions of tropical grasses.

Journal Animal Science, v.79, p.2439-2448, 2001.

LAZZARINI, I.; DETMANN, E.; SAMPAIO, C.B.; PAULINO, M.F.; VALADARES FILHO, S.C.; SOUZA, M.A.; OLIVEIRA, F.A. Intake and digestibility in cattle fed low-quality tropical forage and supplemented with nitrogenous compounds. Revista Brasileira de Zootecnia, v.38, n.10, p.2021-2030, 2009.

PAULINO, M.F.; DETMANN, E.; VALADARES FILHO, S.C.

Suplementação animal em pasto: energética ou protéica? In:

SIMPÓSIO SOBRE MANEJO ESTRATÉGICO DA PASTAGEM, 3, 2006, Viçosa, MG. Anais... Viçosa, MG, 2006. p.359-392.

POPPI, D.P.; McLENNAN, S.R. Protein and energy utilization by ruminants at pasture. Journal of Animal Science, v.73, p.278-290, 1995.

QUEIROZ, D.S.; GOMIDE, J.A.; MARIA, J. Avaliação da folha e do colmo de topo e base de perfilhos de três gramíneas forrag eiras. 2. Anatomia. Revista brasileira de zootecnia, v.29, n.1, p.61-68, 2000.
RAMALHO, T.R.A. Suplementação protéica ou energética para bovinos recriados em pastagens tropicais. 2006. 64p. Dissertação (Mestrado em Ciência Animal e pastagens) Universidade de São Paulo, Escola superior de Agricultura Luiz de Queiroz, Piracicaba.

REIS, R.A.; RUGGIERI, A.C.; CASAGRANDE, D.R. PASCOA, A.G. Suplementação da dieta de bovinos de corte como estratégia do manejo das pastagens. Revista Brasileira de Zootecnia, v.38, p.147-159, 2009.

RESENDE, F.D.; SAMPAIO, R.L.; SIQUEIRA, G.R.; REIS, R.A.; FARIA, M.H.; FERREIRA, L.H. Estratégias de suplementação na recria e terminação de bovinos de corte. Efeitos do nível de suplementação na recria sobre o desempenho na terminação. In: REUNIÃO DA SOCIEDADE BRASILEIRA DE ZOOTECNIA, 45, 2008. Anais... Lavras: Sociedade Brasileira de Zootecnia.

SANTOS, M.E.R.; FONSECA, D.M.; OLIVEIRA, I.M. CASAGRANDE, D.C.; BALBINO, E.M.; FREITAS, F.P. Correlações entre número de perfilhos, índice de tombamento, massa dos componentes morfológicos e valor nutritivo da forragem em pastos diferidos de capim-braquiária. Revista Brasileira de Zootecnia, v.39, n.3, p.487-493, 2010b.

SANTOS, M.E.R.; FONSECA, D.M.; BALBINO, E.M.; GOMES, V.M.; SILVA, S.P. Correlações entre características estruturais e valor nutritivo de perfilhos em pastos de capim-braquiária diferidos e adubados com nitrogênio. Revista Brasileira de Saúde e Produção Animal [Online], v.11, n.3, p.595-605, 2010. 
SANTOS, M.E.R.; FONSECA, D.M.; EUCLIDES, V.P.B. NASCIMENTO JUNIOR, D.; QUEIROZ, A.C.;

RIBEIRO JUNIOR, J.I. Características estruturais e índice de tombamento de Brachiaria decumbens cv. Basilisk em pastagens diferidas. Revista Brasileira de Zootecnia, v.38, n.4, p.626-634, 2009.

SANTOS, E.D.G.; PAULINO, M.F.; QUEIROZ, D.S.; FONSECA, D.M.; VALADARES FILHO, S.C.; LANA, R.P. Avaliação de pastagem diferida de Brachiaria decumbens Stapf. 2.

Disponibilidade de forragem e desempenho animal durante a seca.

Revista Brasileira de Zootecnia, v.33, n.1, p.214-224, 2004.
VIEIRA, B.R. Manejo do pastejo e suplementação nas águas e seus efeitos em sistemas de terminação de novilhas na seca. 2011. 119p. Tese (Doutorado em Zootecnia) Universidade Estadual Paulista, Faculdade de Ciências Agrárias e Veterinária, Jaboticabal.

Data de recebimento: 10/11/2011

Data de aprovação: 15/05/2012 